\title{
Low Amniotic Fluid Index at Term as a Predictor of Adverse Perinatal Outcome
}

\author{
Bachhav Asavari Ashok • Waikar Manjushri
}

Received: 30 August 2013/Accepted: 4 November 2013/Published online: 18 December 2013

(C) Federation of Obstetric \& Gynecological Societies of India 2013

\begin{abstract}
Aim To determine whether an antepartum low amniotic fluid index (AFI) is a predictor of adverse perinatal outcome in normal pregnancy and to determine a threshold level of AFI that could predict an adverse outcome.

Methods This was a prospective study conducted among 180 pregnant women at 37-40 weeks of gestation with no known obstetric or medical complications with an AFI $\leq 5$ th percentile. The results were statistically analyzed and compared.

Results In the control group, the mean AFI was $10.14 \mathrm{~cm}$ and in the study group, it was $4.14 \mathrm{~cm} .65 \%$ patients in the study group and $24 \%$ in the control group had a nonreactive non-stress Test. In the control group, $53 \%$ of patients were induced for reasons other than oligohydramnios, while in the study group, $86 \%$ of patients were
\end{abstract}

Bachhav A. A., Medical Officer (Obstetrics and Gynecology) Civil Hospital-Nasik, Nasik, India

Waikar M., Associate Professor

Department of Obstetrics and Gynaecology, Indira Gandhi

Government Medical College, Nagpur, India

Bachhav A. A. ( $\square$ ), Medical Officer (Obstetrics and Gynecology) Tulshi Hospital, N.D. Patel Road, Opposite Telephone Exchange, Nasik 422001, India

e-mail: asavari.b@gmail.com induced for oligohydramnios. Among the control group, $33 \%$ had a LSCS, while $67 \%$ delivered vaginally; and in the study group, $34 \%$ delivered vaginally and $66 \%$ had a LSCS. In our study, a 5-min APGAR $<7$ was seen in $34 \%$ in the study group and $11 \%$ in the control group. $33 \%$ neonates in the control group and $64 \%$ in the study group had birth weights $<2.5 \mathrm{~kg}$.

Conclusions In the presence of oligohydramnios, perinatal morbidity and mortality are high. Determination of AFI is a valuable screening test for predicting fetal distress.

Keywords Amniotic fluid index (AFI) .

Oligohydramnios $\cdot$ Perinatal $\cdot$ Fetal distress

\section{Introduction}

Phelan defined oligohydramnios as amniotic fluid index (AFI) $\leq 5 \mathrm{~cm}$ and borderline oligohydramnios as AFI between 5 and $8 \mathrm{~cm}$ between 36-42 weeks of gestation [1]. Oligohydramnios occurs in about $1-5 \%$ of pregnancies at term [2]. In pregnancies of more than 40 weeks of gestation, the incidence may be more than $12 \%$ as the amniotic fluid volume declines progressively after 41 weeks of gestation [3]. Women with oligohydramnios are more likely to have abnormal or non-reactive FHR tracings, increased incidence of fetal distress, and thus an increased incidence of caesarean sections [4]. Oligohydramnios is also the leading indication for labor induction. Labor 
induction increases cesarean delivery, particularly for primiparous women with an unripe cervix [5]. Oligohydramnios is associated with a high rate of pregnancy complications and increased perinatal morbidity and mortality. Thus, AFI-assessed antepartum or intrapartum would help to identify women who need increased antepartum surveillance for pregnancy complications [6]. However, some studies show that AFI is a poor predictor of adverse perinatal outcome and isolated oligohydramnios should not be the only parameter for predicting perinatal outcome [7]. Keeping in mind the above knowledge, the present study was carried out to find whether oligohydramnios can be used as a predictor of adverse perinatal outcome in noncomplicated pregnancies at term.

\section{Materials and Methods}

This was a prospective study conducted among 180 eligible women recruited from the OPD and Labor ward. The inclusion criteria for the study were pregnancy at 37-42 weeks of gestation with no known obstetric or medical complications. The exclusion criteria were the presence of obstetric or medical complications and an unwillingness to be a part of the study. The women were divided into control and study groups based on AFI. AFI was measured with the four-quadrant technique and those women with $\mathrm{AFI}<5$ th percentile, i.e., AFI of $<5 \mathrm{~cm}$ at term as described by Phelan as oligohydramnios or an amniotic fluid volume of $<500 \mathrm{~mL}$ at $>37$ weeks of gestation, were included in the study group.

Follow-up of patients identified with oligohydramnios was done till they presented in our labor room in active labor (cervical dilation $\geq 3 \mathrm{~cm}$ and with good uterine contractions at the rate of 3-4 $\mathrm{min}^{-1}$ lasting for at least $45 \mathrm{~s}$ ) or were admitted to labor room through the OPD for other indications.

On admission NST was done for all the included patients. Those with non-reactive NST and not in active labor also had BPP done. Documentation of obstetric interventions in the form of induction or augmentation of labor with prostaglandins or pitocin and mode of delivery was done. Documentation of neonatal outcomes in the form of birth weight and APGAR score was also done. Admission to the neonatal unit for perinatal morbidities like APGAR $\leq 7$, seizures, hypoglycemia, hypothermia, hyperbilirubinemia, hypocalcemia, meconium aspiration, respiratory depression, and perinatal mortality was documented.

The results were recorded and tabulated. They were statistically analyzed using Chi square test. In addition, epidemiological parameters like sensitivity, specificity, positive predictive value, and negative predictive value were used at required observations.

\section{Results}

Out of the 180 women included in the study, $54 \%$ in the control group and $60 \%$ in the study group were primiparas. So, both the groups were comparable. While only $19 \%$ women in the control group were at gestational age $>40$ weeks, the study group included $41 \%$ of such women. The mean AFI for the study group was $4.14 \mathrm{~cm}$ and for the control group was $10.14 \mathrm{~cm}$. The non-stress test was non-reactive in $65 \%$ of the patients having AFI $\leq 5$, while only $24 \%$ of patients having AFI $>5$ had a nonreactive NST $\left(\chi^{2}=27.497, p<0.0001\right)$ (Table 1$)$. Only $33 \%$ of patients in the control group delivered by LSCS, while $66 \%$ of patients in the study group delivered by LSCS $\left(\chi^{2}=21.36, p \leq 0.001\right)$ (Table 2). $86 \%$ patients in the study group were induced, while only $53 \%$ patients in the control group were induced $\left(\chi^{2}=19.53, p \leq 0.001\right)$; among the inductions in the control group, 7 (18\%) underwent a LSCS, while in the study group, 38 (61\%) underwent a $\operatorname{LSCS}\left(\chi^{2}=17.539, p \leq 0.001\right)$. In the control group, 7 (24\%) patients underwent LSCS for fetal distress, while in the study group, $32(53 \%)$ underwent LSCS for fetal distress (Table 3). The determination of AFI $\leq 5 \mathrm{~cm}$ as a screening test, in predicting fetal distress during labor requiring LSCS, has a sensitivity of $82 \%$, specificity of $63.3 \%$, positive predictive value of $51 \%$, and negative predictive value of $90 \%$. A better sensitivity $(82 \%)$ and a negative predictive value $(90 \%)$ make it a good screening test. The 5-min APGAR $\leq 7$ was seen in

Table 1 Distribution of NST pattern

\begin{tabular}{lllllr}
\hline NST & \multicolumn{2}{l}{ Control group } & & & \multicolumn{2}{l}{ Study group } \\
\cline { 2 - 3 } & Number & & & Number & $\%$ \\
\hline Reactive & 67 & 76 & 32 & 35 \\
Non-reactive & 23 & 24 & & 58 & 65 \\
Total & 90 & 100 & & 90 & 100 \\
\hline
\end{tabular}

Using Chi square test: $\chi^{2}=27.497 ; p<0.0001$. Result significant

Table 2 Mode of delivery

\begin{tabular}{llllll}
\hline \multicolumn{2}{l}{ Total no. of deliveries $(n=180)$} & & \\
Type of delivery & \multicolumn{2}{l}{ Control group $(n=90)$} & & \multicolumn{2}{l}{ Study group $(n=90)$} \\
\cline { 2 - 3 } & Number & $\%$ & & Number & $\%$ \\
\hline Vaginal & 60 & 66 & & 30 & 34 \\
LSCS & 29 & 33 & & 60 & 66 \\
Forceps & 1 & 1 & & - & - \\
\hline
\end{tabular}

Using Chi square test: $\chi^{2}=21.36 ; p \leq 0.001$. Result significant 
Table 3 Distribution of indications for LSCS

\begin{tabular}{|c|c|c|c|c|}
\hline \multicolumn{5}{|l|}{ Total no. of deliveries $(n=89)$} \\
\hline \multirow[b]{2}{*}{ Indication } & \multicolumn{2}{|c|}{$\begin{array}{l}\text { Control group } \\
(n=29)\end{array}$} & \multicolumn{2}{|c|}{$\begin{array}{l}\text { Study group } \\
(n=60)\end{array}$} \\
\hline & Number & $\%$ & Number & $\%$ \\
\hline Fetal distress & 7 & 24 & 32 & 53 \\
\hline IUGR with oligohydramnios & 4 & 11 & 18 & 30 \\
\hline PROM with non-progress of labor & 4 & 14 & 3 & 5 \\
\hline Incoordinate uterine action & 2 & 7 & - & - \\
\hline CPD & 3 & 10 & - & - \\
\hline Failure of Induction & 4 & 14 & 3 & 5 \\
\hline Elective LSCS & 5 & 20 & 4 & 7 \\
\hline
\end{tabular}

Using Chi square test: $\chi^{2}=6.769 ; p \leq 0.05$. Result significant

Table 4 Distribution of APGAR $<7$

\begin{tabular}{llllll}
\hline APGAR $\leq 7$ & \multicolumn{2}{l}{ Study group $(n=90)$} & & \multicolumn{2}{l}{ Control group $(n=90)$} \\
\cline { 2 - 3 } & Number & $\%$ & & Number & $\%$ \\
\hline $1 \mathrm{~min}$ & 45 & 50 & & 22 & 24 \\
$5 \mathrm{~min}$ & 30 & 34 & & 9 & 10
\end{tabular}

Using the Chi square test: $\chi^{2}=12.857 ; p=0.0003$. Result significant

$34 \%$ in the study group and $10 \%$ in the control group $\left(\chi^{2}=12.857, p=0.0003\right)$ (Table 4$)$. Thirty three percent patients in the control group and $47 \%$ patients in the study group had babies weighing between 2 and $2.4 \mathrm{~kg}$, while $17 \%$ of women in the study group had babies weighing less than $2 \mathrm{~kg}$ and none in the control group had low birth weight babies $\left(\chi^{2}=16.218, p \leq 0.001\right)$. Fourteen percent of babies in the study group had respiratory distress as compared to $6 \%$ in the control group.

Ninety four percent of the neonates in the AFI 2-3 group were admitted to the NICU, while $26 \%$ of those with AFI $3.1-4$ were admitted; in the control group, $14 \%$ in the AFI 5.1-8 group and $6 \%$ in the $8.1-14$ group required NICU admission (Table 5). The above results show that maximum perinatal morbidity in the form of fetal distress and low APGAR scores was seen in the study group with an AFI of 2-3.

\section{Discussion}

In our study, $41 \%$ of patients in the study group who presented with isolated oligohydramnios were admitted at $>40$ weeks. In the study by Gumus et al. [8], gestational age at delivery was 37.7 weeks for the study group and 38.3 weeks for the control group $(p=0.004)$. This result, while being statistically significant, correlates with our
Table 5 Neonatal complications

\begin{tabular}{|c|c|c|c|c|}
\hline \multicolumn{5}{|c|}{ No. of deliveries $(n=180)$} \\
\hline \multirow[b]{2}{*}{ Neonatal complications } & \multicolumn{2}{|c|}{$\begin{array}{l}\text { Control group } \\
(n=90)\end{array}$} & \multicolumn{2}{|c|}{$\begin{array}{l}\text { Study group } \\
(n=90)\end{array}$} \\
\hline & Number & $\%$ & Number & $\%$ \\
\hline Shifted with mother & 80 & 89 & 58 & 64 \\
\hline Low birth weight & - & - & 15 & 16 \\
\hline Respiratory distress & 5 & 6 & 13 & 14 \\
\hline Meconium aspiration & 4 & 1 & 17 & 18 \\
\hline NICU admission & 9 & 10 & 30 & 33 \\
\hline Stillbirths & 1 & 1 & 2 & 3 \\
\hline Neonatal deaths & - & - & 1 & 1 \\
\hline
\end{tabular}

For NICU admissions, applying the Chi square test: $\chi^{2}=13.475$; $p=0.0002$. Result significant

study. Sixty five percent patients in the study group and $24 \%$ in the control group had a non-reactive non-stress test $\left(\chi^{2}=27.497, p<0.0001\right)$. The above result is statistically significant. In the study by Kumar et al. [9], $40 \%$ of patients had non-reactive NSTs, while in the study by Chandra et al. [10], it was $69.23 \%$ and in the study by Sriya et al. [11], it was $41.55 \%$.These studies show that more than half of the patients with AFI $<5$ have nonreactive NSTs. While comparing the incidence of delivery by LSCS in the study and control groups (66 vs. $33 \%$ ), in the study by Jandial et al. [6], $56 \%$ patients underwent LSCS, while $44 \%$ patients delivered vaginally in the study group, although Gumus et al. [8] had a $p=0.096$ (nonsignificant) for the same. While inductions were significantly higher in the study group $(p<0.001)$, Rainford et al. [12] $(p<0.01)$, Jandial et al. [6], and Gumus et al. [8] had a similar finding. These studies shows that oligohydramnios is an independent indication for induction of labor in most institutes. Comparing the incidence of LSCS for inductions in the control and the study groups $(p<0.001)$, the study by Jandial et al. [6] correlates with our study, and the study by Achalabi et al. [13] based on induction of labor in oligohydramnios and its perinatal outcome, had similar outcomes.

The 5-min APGAR score 7 was seen in $34 \%$ in the study group and $10 \%$ in the control group $\left(\chi^{2}=12.857\right.$, $p=0.0003$ ). In the study by Jandial et al. [6], $25 \%$ of patients with AFI $2-3,11.11 \%$ of patients with AFI $>3-4$, and $9.09 \%$ of patients with AFI $>4-5$ had Apgar scores $<7$ at 5 min which is similar to our study, while in the studies by Rainford et al. [12] and Conway et al. [14], the results though comparable were non-significant.

In terms of neonatal morbidity in the form of low birth weight $<2 \mathrm{~kg}(17 \%)$ and NICU admissions for various indications (30 vs. $9 \%$ ), our findings correlate with those 
of Voxman et al. [4], Rainford et al. [12], Gumus et al. [8], and Jandial et al. [6].

\section{Conclusions}

An AFI of $\leq 5 \mathrm{~cm}$ detected after 37 completed weeks of gestation is an indicator of poor perinatal outcome. In the presence of oligohydramnios, the occurrence of non-reactive NST, abnormal FHR tracings during labor, and thick meconium-stained liquor; development of fetal distress; the rate of LSCS; low 5-min APGAR score; low birth weight; and perinatal mortality are high. Determination of AFI can be used as an adjunct to other fetal surveillance methods. It helps to identify those infants at risk of poor perinatal outcome.

Determination of AFI is a valuable screening test for predicting fetal distress in labor requiring cesarean section. It has a sensitivity of $71 \%$, negative predictive value of $82 \%$, specificity of $58 \%$, and positive predictive value of $43 \%$.

\section{References}

1. Phelan JP, Smith CV, Broussard P, et al. Amniotic fluid volume assessment with four quadrant technique at 36-42 weeks of gestation. J Reprod Med. 1987;32:540-2.

2. Moore IR. Clinical assessment of amniotic fluid. Clin Obstet Gynaecol. 1997;40:303-13.
3. Sherer DM, Langer O. Oligohydramnios: use and misuse in clinical management. Ultrasound Obstet Gynaecol. 2001;18: $410-1$.

4. Voxman EG, Tran S, Wing DA. Low amniotic fluid index as a predictor of adverse perinatal outcome. J Perinatol. 2002;22: 282285.

5. Leeman L, Almond D. Isolated oligohydramnios at term: is induction indicated? J Fam Pract. 2005;54(1):25-32.

6. Jandial C, Gupta S, Sharma S et al. Perinatal outcome after antepartum diagnosis of oligohydramnios at or beyond 34 weeks of gestation. JK Sci 2007;9(4).

7. Zhang J, Troendle J, Meikle S, et al. Isolated oligohydramnios is not associated with adverse perinatal outcomes. BJOG. 2004; 111(3):220-5.

8. Gumms II, Koktener A, Turhan NO. Perinatal outcomes of pregnancies with borderline amniotic fluid index. Arch Gynecol Obstet. 2007;276(1):17-9.

9. Kumar P, Iyer S, Ramkumar V. Amniotic fluid index-a new ultrasound assessment of amniotic fluid. J Obstet Gynaecol India. 1991;41(1):10-2.

10. Chandra P, Kaur SP, Hans DK, et al. The impact of amniotic fluid volume assessed intrapartum on perinatal outcome. Obstet Gynaecol. 2000;5(8):178-81.

11. Sriya R, Singhai S, Rajan M, et al. Perinatal outcome in patients with amniotic fluid index: $5 \mathrm{~cm}$. J Obstet Gynaecol India. 2001;51(5):98-100.

12. Rainford M, Adair R, Scialli AR, et al. Amniotic fluid index in the uncomplicated term pregnancy. Prediction of outcome. J Reprod Med. 2001;46(6):589-92.

13. Achalabi HA, Obeidat BR, Jallad MF, et al. Induction of labor and perinatal outcome: the impact of the amniotic fluid index. Eur J Obstet Gynecol Reprod Biol. 2006;129(2):124-7.

14. Conway DL, Adkins WB, Schroeder B, et al. Isolated oligohydramnios in the term pregnancy: is it a clinical entity. J Matern Fetal Med. 1998;7:197-200. 